\title{
RECURSOS TURÍSTICOS Y ATRACTIVOS TURÍSTICOS: CONCEPTUALIZACIÓN, CLASIFICACIÓN Y VALORACIÓN ${ }^{1}$
}

\author{
Diego Navarro \\ Universidad del Aconcagua. Argentina
}

\section{RESUMEN}

A partir de las definiciones disponibles de recursos turísticos y atractivos turísticos, se identifican coincidencias, excesos y omisiones: la variable funcional y el estado de conversión definen la diferencia. Luego, se propone una clasificación de recursos (con base en enfoques sistémicos y tipologías de la UNESCO) y de atractivos (en consideración del valor de sus recursos y representaciones de base así como de la capacidad o necesidad de ser intervenidos). Se plantean además herramientas de valoración para ambas categorías dependientes de las características destacables para los recursos y en virtud de las gestiones realizadas para los atractivos.

Palabras clave: recurso, atractivo, concepto, clasificación, valoración.

\section{Tourist resources and tourist attractions: conceptualization, classification and assessment}

\begin{abstract}
Based on available definitions of tourist resources and tourist attractions, several coincidences, excesses and omissions are identified: the functional variable and the conversion state define the difference between resources and attractions. Then, two classifications are proposed for both categories: resources (considering system approaches and UNESCO typology) and attractions (attending the assessment of its resources and
\end{abstract}

Recibido: 8 de noviembre de 2013

Devuelto para su revisión: 13 de mayo de 2014

Aceptado: 25 de junio de 2014

Consejo de Investigaciones de la Universidad del Aconcagua. Catamarca, 147. 5500 MENDOZA (Argentina).E-mail: navarrodrazich@yahoo.com

1 Este artículo constituye un subproducto del proyecto bianual de investigación «Modelos de gestión pública de recursos turísticos: el caso argentino», financiado por el CIUDA-Consejo de Investigaciones de la Universidad del Aconcagua (Mendoza, Argentina) y dirigido por el autor. 
representations as well as the capacity or necessity of being managed). Moreover, assessment tools are propounded for both study objects in view of remarkable characteristics (for resources) and actions taken (for attractions).

Key words: resource, attraction, concept, classification, assessment.

La gestión del turismo implica una cantidad y variedad de acciones público-privadas posibles y usuales: elaboración de paquetes y macroproductos; legislación y certificación de calidad; control y fiscalización de establecimientos turísticos; promoción y comercialización; investigación y planificación; formación y capacitación; concientización e información; fomento de inversiones, etc. El presente trabajo parte de una de las instancias iniciales de la gestión pública y privada del turismo: la producción o diseño de atractivos turísticos.

La elección de este tema se basa en diversas causas:

1. desde un punto de vista teórico y académico, la ostensible escasez de conocimientos específicos y situados para decidir intervenciones prácticas y para la formación profesional en un tema central de la planificación y la gestión turística;

2. desde una perspectiva ambiental y cultural, la responsabilidad de garantizar la protección de bienes naturales y culturales durante su aprovechamiento como atractivos turísticos;

3. desde una óptica social y económica, la extendida insatisfacción experimentada por turistas y aún durante sus visitas, en términos de accesibilidad, comodidad, interpretación, apreciación y participación.

4. desde un enfoque político y estratégico, la necesidad de contar con atractivos turísticos valiosos, que permitan conformar una oferta de macroproductos relevantes y, a la vez, reducir la insatisfacción de la experiencia turística mediante el ajuste entre oferta disponible y oferta promocionada (esta última, objeto estelar de la gestión pública del turismo de los últimos tiempos).

\section{RECURSOS TURÍSTICOS}

Resulta pertinente comenzar por la familiarización con las categorías conceptuales de recurso turístico y atractivo turístico. Varias obras reconocidas en Hispanoamérica hacen uso extensivo de estas expresiones y ofrecen referencias conceptuales.

Así, Ramírez Blanco asimila atractivo turístico con recurso turístico y, en base a Zimmermann (1957), los define como los «elementos naturales, objetos culturales o hechos sociales, que mediante una adecuada y racionada actividad humana pueden ser utilizados como causa suficiente para motivar el desplazamiento turístico» (1998: 61).

En el «Diccionario de terminología turística» de la Dirección Nacional de Turismo argentina se lee que un atractivo turístico «es el elemento natural, cultural, deportivo o de cualquier otro tipo que pueda generar suficiente interés para atraer turistas» (DNT, 1970, s./f.). 
Por su parte, Acerenza identifica los atractivos turísticos como el componente más importante del producto turístico «por cuanto son los que determinan la selección, por parte del turista, del punto del destino de su viaje, y son los que generan por tanto, una corriente turística hacia su localización«. Apunta asimismo que «constituyen el principal motivo para que el turista lo visite [al destino]» y «son capaces de satisfacer las motivaciones primarias de viaje de los turistas» (1984: 211 y 213).

Boullón (1985: 44) señala que los atractivos turísticos conforman la «materia prima» que permite que la planta turística (equipamiento e instalaciones) opere.

También Gurría di Bella equipara atractivo turístico y recurso turístico, como un mismo objeto con distinta denominación según el sujeto que lo refiera. El autor señala que ambos suponen una «serie de características [propia de «todo lugar que constituya un destino turístico»] que motive el desplazamiento temporal de los viajeros. Estas características desde el punto de vista del visitante se denominan atractivos turísticos, porque son los que llaman y atraen su atención. Desde el punto de vista de la región visitada, estos atractivos forman parte de los recursos turísticos, porque constituyen lo que se puede ofrecer al visitante» (1991: 48).

En una publicación de la OMT (Organización Mundial del Turismo) y con base en Zimmermann (1933) se entiende por recurso turístico a «todos los bienes y servicios que, por intermedio de la actividad del hombre y de los medios con que cuenta, hacen posible la actividad turística y satisfacen las necesidades de la demanda» (Sancho, 1998: 186). Se trata de una noción inclusiva de las prestaciones de servicios: elemento del sistema turístico distinto del recurso turístico, incluso en esa misma publicación (Sancho, 1998: 187; figura 9.3.).

En otra publicación de la OMT sobre el Modelo FAS (factores-atractores-sistemas de apoyo), se entiende por factor o recurso turístico «aquellos elementos que por sí mismos o en combinación con otros pueden despertar el interés para visitar una determinada zona o región. Es decir, sería todo elemento capaz de generar desplazamientos turísticos» (OMT, s.f.: 4). Por otra parte, y con una débil diferenciación de la idea de recurso turístico, define a los atractores turísticos como «aquellos elementos naturales, culturales o realizados por la mano de un hombre que combinados con los recursos turísticos son capaces de generar un desplazamiento a un determinado destino turístico» (OMT, s.f.: 35).

Por último, el «Diccionario de Turismo, Hotelería y Transporte» ofrece una definición de atractivo turístico; considera que se trata de un «objeto o acontecimiento capaz de motivar a un turista a abandonar su domicilio habitual para trasladarse a conocerlo» (Wallingre y Toyos, 2010: 31). Respecto de recurso turístico, indica que consiste en «todo elemento natural o no, capaz de motivar un desplazamiento turístico», a la vez que advierte que «algunos autores utilizan indistintamente los términos recurso y a. tur. [sic.]». La misma fuente, incluye una definición de Domínguez de Nakayama que asocia recurso turístico a «elementos con suficiente valor, atractivos, aptos y disponibles, sobre los cuales una comunidad puede basar su actividad turística» (1994: 24). Apunta asimismo que para Altés Machín los recursos turísticos son aquellos «atractivos que, en el contexto de un destino, pueden generar un interés entre el público, determinar la elección y motivar el desplazamiento o la visita» y retoma la idea de que los recursos turísticos son «la base sobre la que se desarrolla la actividad turística» (1995: 33). 
Con divergencias y superposiciones, existe una noción sobre qué son los recursos y atractivos turísticos. Una doble vertiente conceptual atraviesa las definiciones revisadas. Los atractivos turísticos y los recursos turísticos:

- Implican bienes naturales o culturales (aspecto formal)

- Poseen la capacidad de provocar la visita (aspecto funcional).

Respecto de la clasificación de atractivos y recursos se observan que diversos autores practican distintos agrupamientos:

\begin{tabular}{|c|c|c|}
\hline \multicolumn{3}{|c|}{ Ramírez Blanco (1998: 62) basado en IMIT (1974) } \\
\hline \multirow{8}{*}{\multicolumn{2}{|c|}{ Recursos naturales }} & Clima \\
\hline & & Mares \\
\hline & & Lagos \\
\hline & & Ríos \\
\hline & & Montañas \\
\hline & & Bosques \\
\hline & & Praderas \\
\hline & & Playas \\
\hline \multirow{21}{*}{$\begin{array}{l}\text { Recursos } \\
\text { socioculturales }\end{array}$} & \multirow{6}{*}{$\begin{array}{l}\text { Obras de creación } \\
\text { estética (pasadas y } \\
\text { presentes) }\end{array}$} & Pintura \\
\hline & & Escultura \\
\hline & & Música \\
\hline & & Danza \\
\hline & & Artesanía \\
\hline & & Arquitectura \\
\hline & \multirow{14}{*}{$\begin{array}{l}\text { Obras derivadas } \\
\text { de la técnica y de } \\
\text { la experimentación } \\
\text { científica (antiguas y } \\
\text { modernas) }\end{array}$} & Edificios \\
\hline & & Presas \\
\hline & & Diques \\
\hline & & Puentes \\
\hline & & Viaductos \\
\hline & & Caminos subterráneos \\
\hline & & Otros medios \\
\hline & & Complejos urbanísticos-industriales \\
\hline & & Centros deportivos \\
\hline & & Centros de exposiciones \\
\hline & & Centros de enseñanza e investigación \\
\hline & & Congresos \\
\hline & & Seminarios \\
\hline & & Desfiles \\
\hline & \multicolumn{2}{|c|}{$\begin{array}{l}\text { Eventos y espectáculos públicos y privados, permanentes o } \\
\text { eventuales }\end{array}$} \\
\hline
\end{tabular}




\begin{tabular}{|c|c|}
\hline \multicolumn{2}{|c|}{ Ramírez Blanco (1998: 62) basado en CIT (s./f.) } \\
\hline \multirow{6}{*}{ Naturales } & Clima \\
\hline & Bellezas naturales \\
\hline & Parques \\
\hline & Playas \\
\hline & Caza \\
\hline & Pesca \\
\hline \multirow{5}{*}{ Culturales } & Arqueología \\
\hline & Arte prehispánico \\
\hline & Arte colonial \\
\hline & Arte moderno y contemporáneo \\
\hline & Tradiciones y folklore \\
\hline \multirow{8}{*}{ Diversiones } & Centro de diversión y esparcimiento \\
\hline & Teatros \\
\hline & Cines \\
\hline & Centros nocturnos \\
\hline & Fiesta brava \\
\hline & Fiesta charra \\
\hline & Eventos deportivos \\
\hline & Hipódromos \\
\hline \multirow{2}{*}{ Centros de salud, recuperación y descanso } & Centros balneoterapéuticos \\
\hline & Centros y casas de salud \\
\hline
\end{tabular}

\begin{tabular}{|c|c|c|}
\hline \multicolumn{3}{|c|}{ Acerenza (1984: 211 y 213$)$} \\
\hline \multirow{8}{*}{$\begin{array}{l}\text { Atractivos de } \\
\text { sitio }\end{array}$} & \multirow{4}{*}{ Naturales } & Clima \\
\hline & & Paisaje \\
\hline & & Flora \\
\hline & & Fauna \\
\hline & \multirow{2}{*}{ Usos y costumbres } & Manifestaciones culturales \\
\hline & & Vestigios de culturas antiguas \\
\hline & \multirow{2}{*}{ Infraestructura } & Características generales de las aglomeraciones urbanas \\
\hline & & Realizaciones técnicas contemporáneas \\
\hline \multirow{5}{*}{$\begin{array}{l}\text { Atractivos de } \\
\text { eventos }\end{array}$} & \multicolumn{2}{|c|}{ Ferias y exposiciones } \\
\hline & \multicolumn{2}{|c|}{ Congresos y convenciones } \\
\hline & \multirow{3}{*}{$\begin{array}{l}\text { Acontecimientos } \\
\text { programados }\end{array}$} & Evento deportivo \\
\hline & & Festival \\
\hline & & Certamen de belleza \\
\hline
\end{tabular}




\begin{tabular}{|c|c|}
\hline \multicolumn{2}{|c|}{ Boullón (1985: 45-46) basado en OEA-CICATUR ${ }^{2}$} \\
\hline \multirow{12}{*}{ Sitios naturales } & Montañas \\
\hline & Planicies \\
\hline & Costas \\
\hline & Lagos, lagunas y esteros \\
\hline & Ríos y arroyos \\
\hline & Caídas de agua \\
\hline & Grutas y cavernas \\
\hline & Lugares de observación de flora y fauna \\
\hline & Lugares de caza y pesca \\
\hline & Caminos pintorescos \\
\hline & Termas \\
\hline & Parques nacionales y reservas de flora y fauna \\
\hline \multirow{4}{*}{$\begin{array}{l}\text { Museos y manifestaciones culturales } \\
\text { históricas }\end{array}$} & Museos \\
\hline & Obras de arte y técnica \\
\hline & Lugares históricos \\
\hline & Ruinas y sitios arqueológicos \\
\hline \multirow{7}{*}{ Folklore } & Manifestaciones religiosas y creencias populares \\
\hline & Ferias y mercados \\
\hline & Música y danzas \\
\hline & Artesanías y artes populares \\
\hline & Comidas y bebidas típicas \\
\hline & Grupos étnicos \\
\hline & Arquitectura popular y espontánea \\
\hline \multirow{5}{*}{$\begin{array}{l}\text { Realizaciones técnicas, científicas } \\
\text { o artísticas contemporáneas }\end{array}$} & Explotaciones mineras \\
\hline & Explotaciones agropecuarias \\
\hline & Explotaciones industriales \\
\hline & Obras de arte y técnica \\
\hline & Centros científicos y técnicos \\
\hline \multirow{6}{*}{ Acontecimientos programados } & Artísticos \\
\hline & Deportivos \\
\hline & Ferias y exposiciones \\
\hline & Concursos \\
\hline & Fiestas religiosas y profanas \\
\hline & Carnavales \\
\hline
\end{tabular}

2 La clasificación de Boullón reproduce la propuesta de la OEA-CICATUR, centro de formación turística pionero en las Américas; acaso este motivo explique que sus productos intelectuales, como este ordenamiento, hayan alcanzado un fuerte arraigo en América Latina. 


\begin{tabular}{|c|c|c|}
\hline \multicolumn{3}{|c|}{ Gurría di Bella (1991: 48-51) basado en García Silberman (1970) } \\
\hline \multirow{14}{*}{$\begin{array}{l}\text { Atractivos } \\
\text { geomorfológicos }\end{array}$} & \multirow{4}{*}{ Litorales } & Rocas e islas \\
\hline & & Playas \\
\hline & & Acantilados \\
\hline & & Desembocaduras de ríos \\
\hline & \multicolumn{2}{|c|}{ Lagunas y depósitos de agua } \\
\hline & \multirow{2}{*}{ Corrientes de agua } & Superficiales (cañones y cascadas) \\
\hline & & Subterráneas (manantiales, grutas y cenotes) \\
\hline & \multirow{3}{*}{ Vulcanismo } & Cráteres \\
\hline & & Aguas termales y minerales \\
\hline & & Géisers \\
\hline & \multirow{4}{*}{ Relieves } & Montañas \\
\hline & & Barrancas y cañones \\
\hline & & Planicies \\
\hline & & Dunas \\
\hline \multirow{4}{*}{$\begin{array}{l}\text { Atractivos } \\
\text { biogeográficos }\end{array}$} & \multirow{2}{*}{ Agrupaciones vegetales } & Selvas \\
\hline & & Bosques \\
\hline & \multirow{2}{*}{ Agrupaciones animales } & Fauna silvestre \\
\hline & & Zonas de caza \\
\hline \multirow{25}{*}{$\begin{array}{l}\text { Atractivos } \\
\text { culturales }\end{array}$} & \multirow{6}{*}{ Históricos } & Zonas arqueológicas \\
\hline & & Arquitectura antigua \\
\hline & & Lugares históricos \\
\hline & & Poblados típicos \\
\hline & & Folklore \\
\hline & & Fiestas tradicionales \\
\hline & \multirow{7}{*}{$\begin{array}{l}\text { Contemporáneos } \\
\text { (no comerciales) }\end{array}$} & Centro de convenciones \\
\hline & & Institutos de enseñanza \\
\hline & & Bibliotecas \\
\hline & & Museos y pinturas murales \\
\hline & & Obras monumentales \\
\hline & & Invernaderos \\
\hline & & Zoológicos \\
\hline & \multirow{12}{*}{$\begin{array}{l}\text { Contemporáneos } \\
\text { (comerciales) }\end{array}$} & Parques de diversiones \\
\hline & & Balnearios \\
\hline & & Espectáculos culturales y deportivos \\
\hline & & Campo deportivos \\
\hline & & Exposiciones nacionales e internacionales \\
\hline & & Mercados de artesanías \\
\hline & & Comercios \\
\hline & & Centros de salud \\
\hline & & Ferias y carnavales \\
\hline & & Celebraciones religiosas \\
\hline & & Casinos \\
\hline & & Concursos y competencias \\
\hline
\end{tabular}




\begin{tabular}{|c|c|}
\hline \multicolumn{2}{|c|}{ Sancho (1998: 132) basada en Swarbrooke (1995) para atracciones } \\
\hline \multirow{7}{*}{ Naturales } & Playas \\
\hline & Cuevas \\
\hline & Ríos \\
\hline & Lagos \\
\hline & Bosques \\
\hline & Flora \\
\hline & Fauna \\
\hline \multirow{5}{*}{$\begin{array}{l}\text { Creadas por el hombre, no diseñadas con la intención de } \\
\text { atraer visitantes }\end{array}$} & Catedrales \\
\hline & Iglesias \\
\hline & Casas históricas \\
\hline & Monumentos \\
\hline & Jardines históricos \\
\hline \multirow{9}{*}{$\begin{array}{l}\text { Creadas por el hombre, diseñadas con la intención de } \\
\text { atraer visitantes }\end{array}$} & Parques de atracciones \\
\hline & Parques temáticos \\
\hline & Museos \\
\hline & Centros de exhibición \\
\hline & Casinos \\
\hline & Centros de ocio \\
\hline & Balnearios \\
\hline & Lugares de picnic \\
\hline & Safari park \\
\hline \multirow{6}{*}{ Eventos especiales } & Festivales de arte \\
\hline & Encuentros deportivos \\
\hline & Mercados y ferias \\
\hline & Folklore \\
\hline & Aniversarios históricos \\
\hline & Eventos religiosos \\
\hline
\end{tabular}

\begin{tabular}{|l|l|}
\hline \multicolumn{2}{|c|}{ Sancho (1998: 186) basada en Clawson y Kntestch (1966) para recursos } \\
\hline \multirow{2}{*}{ Recursos orientados al usuario } & Parque urbano \\
\cline { 2 - 2 } & Parque recreativo \\
\hline \multirow{2}{*}{ Recursos recreativos de tipo intermedio } & Parque nacional \\
\cline { 2 - 2 } & Zona protegida \\
\cline { 2 - 2 } & Espacio natural \\
\hline Esparcimiento y ocio basado en el recurso & \\
\hline
\end{tabular}

\begin{tabular}{|l|l|}
\hline \multicolumn{2}{|c|}{ Sancho (1998: 187) basada en Burkart y Medlik (1981) para recursos } \\
\hline Resource-based & (independiente de la localización) \\
\hline Resource user-oriented & (dependiente de la localización) \\
\hline
\end{tabular}




\begin{tabular}{|c|c|c|c|c|}
\hline \multicolumn{5}{|c|}{ OMT (s.f.: 6-25) para recursos turísticos } \\
\hline \multirow{13}{*}{ Naturalia } & \multirow{6}{*}{ Tierra } & \multirow{6}{*}{ Relieve } & \multirow{2}{*}{$\begin{array}{l}\text { Áreas } \\
\text { litorales }\end{array}$} & Litoral \\
\hline & & & & Costa \\
\hline & & & \multirow{4}{*}{ Interior } & Sistema glaciar \\
\hline & & & & Sistema periglaciar \\
\hline & & & & Sistema húmedo \\
\hline & & & & Sistema árido \\
\hline & \multirow{5}{*}{ Agua } & \multirow{5}{*}{\multicolumn{2}{|c|}{ Hidrografía }} & Mares y océanos \\
\hline & & & & Ríos \\
\hline & & & & Lagos \\
\hline & & & & Glaciares \\
\hline & & & & Aguas termales \\
\hline & \multirow{2}{*}{ Otros } & & & Clima \\
\hline & & & & Vegetación y fauna \\
\hline \multirow{10}{*}{ Humania } & \multicolumn{4}{|c|}{ Recursos humanos } \\
\hline & \multirow{9}{*}{$\begin{array}{l}\text { Herencia } \\
\text { cultural }\end{array}$} & \multirow{6}{*}{\multicolumn{2}{|c|}{ Histórico-artísticos }} & Restos prehistóricos \\
\hline & & & & Grandes culturas de la antigüedad \\
\hline & & & & Edad Media \\
\hline & & & & $\begin{array}{l}\text { Culturas encontradas por los descubridores } \\
\text { europeos }\end{array}$ \\
\hline & & & & Cultura árabes \\
\hline & & & & Ciudades históricas \\
\hline & & \multirow{3}{*}{\multicolumn{2}{|c|}{$\begin{array}{l}\text { Tradición y } \\
\text { costumbres }\end{array}$}} & Fiestas populares \\
\hline & & & & Gastronomía \\
\hline & & & & Valores religiosos e ideológicos \\
\hline Capitalia & & & & \\
\hline
\end{tabular}

\begin{tabular}{|l|l|}
\hline \multicolumn{2}{|c|}{ OMT (s.f.: 35-44) para atractores turísticos } \\
\hline \multirow{4}{*}{ Naturales } & Termalismo \\
\cline { 2 - 2 } & Talasoterapia \\
\cline { 2 - 3 } & Cruceros \\
\cline { 2 - 3 } & Espacios naturales \\
\hline \multirow{4}{*}{ Culturales } & Ciudades históricas \\
\cline { 2 - 3 } & Museos \\
\cline { 2 - 2 } & Festivales \\
\hline \multirow{2}{*}{ Realizados por el hombre o «man made» } & Parques temáticos \\
\cline { 2 - 2 } & MICE (meetings, congreso, incentive, exhibitions) \\
\hline
\end{tabular}




\begin{tabular}{|c|c|c|}
\hline \multicolumn{3}{|c|}{ Altés Machín (1995: 33) en Wallingre y Toyos (2010: 203) para recurso turístico } \\
\hline \multirow{12}{*}{ Relacionados con la naturaleza } & \multirow{6}{*}{ Agua } & Mar \\
\hline & & Playa \\
\hline & & Río \\
\hline & & Cascada \\
\hline & & Catarata \\
\hline & & Fondo marino \\
\hline & \multirow{6}{*}{ Tierra } & Paisaje \\
\hline & & Valle \\
\hline & & Montaña \\
\hline & & Desierto \\
\hline & & Flora \\
\hline & & Fauna \\
\hline \multirow{13}{*}{ Relacionados con la historia } & \multicolumn{2}{|c|}{ Iglesia } \\
\hline & \multicolumn{2}{|c|}{ Abadía } \\
\hline & \multicolumn{2}{|c|}{ Catedral } \\
\hline & \multicolumn{2}{|c|}{ Palacio } \\
\hline & \multicolumn{2}{|c|}{ Castillo } \\
\hline & \multicolumn{2}{|c|}{ Fortaleza } \\
\hline & \multicolumn{2}{|c|}{ Ciudad monumental } \\
\hline & \multicolumn{2}{|l|}{ Puente } \\
\hline & \multicolumn{2}{|c|}{ Acueducto } \\
\hline & \multicolumn{2}{|c|}{ Conjunto arqueológico } \\
\hline & \multicolumn{2}{|c|}{ Conjunto artístico } \\
\hline & \multicolumn{2}{|c|}{ Obra de arte } \\
\hline & \multicolumn{2}{|c|}{ Museo } \\
\hline \multirow{7}{*}{ Relacionados con la cultura viva } & \multicolumn{2}{|c|}{ Forma de vida } \\
\hline & \multicolumn{2}{|c|}{ Tradición } \\
\hline & \multicolumn{2}{|c|}{ Gastronomía } \\
\hline & \multicolumn{2}{|c|}{ Folklore } \\
\hline & \multicolumn{2}{|c|}{$\begin{array}{l}\text { Manifestaciones contemporáneas (técnicas, artísticas, } \\
\text { culturales) }\end{array}$} \\
\hline & \multicolumn{2}{|c|}{ Fiestas } \\
\hline & \multicolumn{2}{|c|}{ Celebraciones } \\
\hline
\end{tabular}


La comparación de las propuestas clasificatorias de las distintas fuentes sugiere varias lecturas:

- Todas las propuestas focalizan en el aspecto formal y ninguna en el funcional.

- Todas las clasificaciones destinan una categoría precisa para los bienes naturales.

- La agrupación o subdivisión de los bienes culturales varía de un autor a otro.

- Obtienen una débil presencia los bienes intangibles, los bienes muebles, las personas y los grupos humanos: recursos turísticos de relieve en numerosos destinos del mundo.

- Ocasional inclusión de elementos (infraestructura, estructura, instalaciones, recursos humanos, capital financiero) que desempeñan otras funciones en el sistema turístico, antes que motivar la visita.

Por una parte, y a fin de poner luz sobre los aspectos formales señalados, se recurre a una propuesta sistémica del fenómeno turístico de nuestra autoría (Navarro, 2007b: 48-52). En tal ocasión, se entendió al turismo como la interacción entre un Subsistema de Origen (visitantes) y un Subsistema de Destino (constructo socionatural receptor). A su vez, este último fue desagregado en nuevos subsistemas (natural, artificial, social, cultural, económico y político), cada uno de los cuales posee recursos turísticos.

\begin{tabular}{|l|l|}
\hline \multicolumn{3}{|c|}{$\begin{array}{l}\text { COMPONENTES del SUBSISTEMA de DESTINO } \\
\text { (Navarro, 2007b: 48-52) }\end{array}$} \\
\hline Componente & Recursos \\
\hline Natural & Clima, hidrografía, relieve, flora, fauna, paisaje natural \\
\hline Artificial & Bienes inmuebles y muebles, paisaje cultural (rural y urbano) \\
\hline Cultural & $\begin{array}{l}\text { Actores (individuales, colectivos, institucionales), productos intangibles y procesos } \\
\text { vinculados con la gastronomía y la medicina, historias y leyendas, cosmovisiones, } \\
\text { ideologías y creencias, juegos y fiestas, deportes, literatura y cine, música y danza, } \\
\text { identidades, prácticas y técnicas, usos y costumbres, valores }\end{array}$ \\
\hline Social & $\begin{array}{l}\text { Actores (individuales, colectivos, institucionales), productos y procesos de la } \\
\text { sociedad civil. }\end{array}$ \\
\hline Económico & $\begin{array}{l}\text { Actores (individuales, colectivos, institucionales), productos y procesos } \\
\text { comerciales (extracción, producción o agropecuarios, transformación o industriales, } \\
\text { prestaciones, intercambios). }\end{array}$ \\
\hline Político & $\begin{array}{l}\text { Actores (individuales, colectivos, institucionales), productos y procesos } \\
\text { gubernamentales. }\end{array}$ \\
\hline
\end{tabular}

Por otra parte, se considera la clasificación del patrimonio de la UNESCO en bienes naturales y culturales. Se trata de una taxonomía que atiende más a la materialidad y movilidad de los recursos (variables útiles para la identificación y gestión) que a la enumeración siempre incompleta de figuras posibles. Efectivamente, concibe bienes tangibles o intangibles en tanto se manifiesten en expresiones materiales; así como bienes muebles o inmuebles en tanto puedan desplazarse o ser desplazados o permanecen en un espacio puntual de la superficie terrestre. 


\section{CLASIFICACIÓN del PATRIMONIO de la UNESCO ${ }^{2}$}

(Abal de Ruso, 1997 y Ruiz, 2005: 13-14)

\begin{tabular}{|l|l|l|}
\hline \multicolumn{3}{|l|}{ Bien natural } \\
\hline \multirow{3}{*}{ Bien cultural } & Tangible & Mueble \\
\cline { 2 - 3 } & Intangible & Inmueble \\
\hline
\end{tabular}

Con pretensiones superadoras y simplificadoras de los modelos revisados, y a fin de facilitar su identificación y gestión, se propone aquí luego una clasificación formal de recursos turísticos que combina la clasificación desarrollada del Subsistema de Destino y la clasificación de patrimonio de la UNESCO:

\begin{tabular}{|l|l|l|l|}
\hline \multicolumn{3}{|c}{ CLASIFICACIÓN FORMAL de RECURSOS TURÍSTICOS } \\
\hline \multirow{3}{*}{ Origen } & Materialidad & Movilidad & Ejemplo \\
\hline \multirow{3}{*}{ Cultural } & \multirow{2}{*}{ Tangible } & Mueble & cóndor, ballena franca austral \\
\cline { 2 - 4 } & \multirow{3}{*}{ Intangible } & Inmueble & cataratas del Iguazú, Lago Nahuel Huapi \\
\cline { 2 - 4 } & \multirow{2}{*}{ Tangible } & Mueble & Tren a las Nubes \\
\cline { 2 - 4 } & Intangible & Inmueble & teatro Colón \\
\hline \multirow{3}{*}{ Humano } & Tangible & Mueble & tango, fútbol, elaboración del vino malbec \\
\cline { 2 - 4 } & & Inmueble & despojos de Eva Perón, momias incaicas \\
\cline { 2 - 4 } & Intangible & & memoria del Gral. San Martín, Corto Maltés \\
\hline
\end{tabular}

Esta propuesta advierte el aspecto formal de los recursos turísticos y pretende salvar aquella débil presencia señalada de bienes intangibles y muebles, de personas y grupos humanos. De un lado, toma las variables de materialidad y movilidad de la UNESCO. De otro lado, considera los componentes sistémicos: 1. los recursos turísticos naturales, anteriores e independientes del hombre, se nutren del subsistema natural; 2. los recursos turísticos culturales, producto del hombre, incluyen elementos de todos los subsistemas excepto del natural; y 3. los recursos turísticos humanos, equivalentes al hombre, toman figuras de los subsistemas cultural, social, económico y político.

Respecto de la materialidad, es interesante destacar que los recursos turísticos intangibles suelen ganar materia y manifestarse en atractivos tangibles (ej.: los cuerpos celestes en el Planetario Galileo Galilei, el automovilista Fangio en el museo homónimo, la cosecha de uvas en la Fiesta de la Vendimia, Mafalda en su monumento). La materialización deli-

3 United Nations Educational, Scientific and Cultural Organization (Organización de Naciones Unidas para la Educación, la Ciencia y la Cultura), Convención para la Protección del Patrimonio Mundial Cultural y Natural, París, 1972. 
berada de recursos turísticos intangibles constituye un procedimiento y una opción central en el diseño o producción de atractivos y una actividad metodológica que reclama estudios en profundidad. Asimismo, el proceso inverso a la materialización, esto es la identificación y gestión de las representaciones asociadas a recursos turísticos materiales, supone un ejercicio intelectual estimulante en ocasión de la conversión del recurso en atractivo.

En relación con la movilidad, obsérvese que aquéllos seres vivos o bióticos (recursos turísticos naturales o humanos) que son móviles (pueden moverse por sí solos) quedan incluidos entre los recursos muebles; y aquéllos inmóviles o sésiles (no pueden moverse por sí solos), entre los recursos inmuebles. Por el contrario, entre los seres o factores abióticos, son recursos muebles aquéllos que pueden ser removidos y son recursos inmuebles aquéllos que no pueden (o no suelen) ser removidos.

También respecto de la movilidad se señala que la condición de mueble facilita el traslado del recurso en muchos casos: una desventaja, en tanto reduce la necesidad de desplazamiento del visitante potencial hacia el destino; pero también una ventaja, en cuanto permite que el recurso mueble (virtud extensiva a los recursos intangibles) se desplace hasta el visitante potencial y alimente el deseo. Por ejemplo, no es necesario viajar a la Argentina para leer libros de Bioy Casares ya que éstos llegan a cualquier parte del mundo; pero este recurso, pertinentemente elaborado (museo, ruta temática, muestra, año temático) puede materializar en atractivos turísticos inmuebles y recurrir al libro como instrumento promocional.

Adviértase asimismo que es posible y frecuente hallar en la realidad asociaciones de recursos turísticos. Así, un paisaje puede incluir recursos naturales, culturales y humanos; un resto arqueológico determinado puede presentar recursos inmuebles de origen animal (fósil), cultural (cerámica) y humanos (esqueleto); ciertas actividades rurales asocian recursos muebles animales (ganado), culturales (herramientas) y humanos (pastor).

Los recursos turísticos humanos constituyen la novedad de esta concepción. La capacidad de provocar visitas turísticas de determinadas personas y colectivos es evidente en los flujos turísticos motorizados por ciertos individuos (artistas y deportistas, líderes políticos y religiosos, científicos e intelectuales), por determinados grupos sociales (ej.: aborígenes y negros, hippies y vaqueros, gitanos y menonitas), tanto actuales como pretéritos y aún de ficción (aunque también clasificables como recursos culturales, los personajes de ficción son incluidos aquí para facilitar su identificación y gestión).

Clasificados con independencia de las otras categorías, los seres humanos contamos con un cuerpo (componente natural), pero también representamos significaciones (componente cultural). Esta doble característica origina también un procedimiento específico de conversión del recurso en atractivo. Asimismo, la clasificación en muebles, inmuebles e intangibles extendidamente coincidirá con personas vivas, restos mortuorios y figuras inmateriales, respectivamente.

En todo caso, la idea de recurso turístico no implica cualquier recurso, sino uno relevante, uno que se distingue de sus pares por alguna particularidad, un primus inter pares al menos (ej.: el cerro Aconcagua no es un cerro más, sino el más alto de los hemisferios occidental y meridional; he aquí su valor). Tal característica provocará la visita en tanto los visitantes consideren que el contacto directo con ese recurso satisfará algún tipo de necesidad, deseo o demanda. Luego, el desplazamiento o la visita, aspecto funcional presente en muchas definiciones, es un efecto antes que una causa: la causa son las características 
relevantes de recurso. Poner el foco en los atributos destacables del recurso permite además un análisis independiente de la respuesta potencial del visitante.

En consecuencia, se entiende por recursos turísticos aquellos:

\begin{tabular}{|c|}
\hline CONCEPTO de RECURSOS TURÍSTICOS \\
\hline Bienes (naturales, culturales y humanos, tangibles e intangibles, muebles e inmuebles) \\
con características relevantes.
\end{tabular}

Atendiendo a las cualidades sobresalientes del recurso, éste puede ser valorado por su relevancia. En este sentido, el CICATUR-OEA (Centro Interamericano de Capacitación Turística de la Organización de Estados Americanos) propuso en 1974 una escala de valoración de recursos turísticos que rápidamente se extendió en Latinoamérica y de uso prácticamente excluyente hasta la actualidad. Aquí, los recursos turísticos son valorados a partir de una única variable: su singularidad en términos geográficos:

\begin{tabular}{|l|l|}
\hline \multicolumn{2}{|c|}{ JERARQUIZACIÓN de RECURSOS TURÍSTICOS basado en CICATUR-OEA } \\
(Cárdenas Tabares, 1991: 47)
\end{tabular}

4 La propuesta de Cárdenas Tabares es una modificación de la original del CICATUR-OEA. 
En un ejercicio intelectual anterior (Navarro, 2010: 40 y 235-240) se observó que el discurso turístico promocional indefectiblemente versa sobre la referidas virtudes de los recursos turísticos. Para comprobarlo, basta con revisar el contenido de folletos, sitios web y guías turísticas, slogans, artículos periodísticos sobre destinos turísticos y crónicas de turistas post-visita, audioguías, carteles y explicaciones de guías turísticos: la referencia al recurso turístico y a sus atributos diferenciales es insoslayable. Se valora que sean únicos, superiores, numerosos, antiguos o novedosos, frecuentes o infrecuentes, variados, significativos, útiles, bellos. En este sentido, se presenta a continuación una propuesta de valoración de recursos turísticos con mayor capacidad evaluativa (aunque no exhaustiva) en tanto comprende un mayor desarrollo de variables: unicidad, superioridad, antigüedad y novedad, frecuencia, diversidad, significación, funcionalidad, sensorialidad.

\begin{tabular}{|c|c|c|}
\hline \multicolumn{3}{|c|}{ VALORACIÓN de RECURSOS TURÍSTICOS } \\
\hline Valor & Ejemplo & Grado \\
\hline \multirow{3}{*}{ Unicidad o singularidad $^{5}$} & \multirow{3}{*}{$\begin{array}{l}\text { Luis F. Leloir es el único premio noble argentino de } \\
\text { Química }\end{array}$} & Alto \\
\hline & & Medio \\
\hline & & Bajo \\
\hline \multirow{3}{*}{ Superioridad absoluta } & \multirow{3}{*}{$\begin{array}{l}\text { Las Rutas del Vino de Mendoza reúnen más bodegas que } \\
\text { otras rutas enoturísticas latinoamericanas. }\end{array}$} & Alto \\
\hline & & Medio \\
\hline & & Bajo \\
\hline \multirow{3}{*}{ Superioridad relativa } & \multirow{3}{*}{ La Patagonia cuenta con muchas especies protegidas. } & Alto \\
\hline & & Medio \\
\hline & & Bajo \\
\hline \multirow{3}{*}{$\begin{array}{l}\text { Antigüedad absoluta } \\
\text { (o valor inaugural) }\end{array}$} & \multirow{3}{*}{$\begin{array}{l}\text { «La Historia Oficial» es la primera película argentina } \\
\text { ganadora de un Oscar. }\end{array}$} & Alto \\
\hline & & Medio \\
\hline & & Bajo \\
\hline \multirow{3}{*}{ Antigüedad relativa } & \multirow{3}{*}{$\begin{array}{l}\text { La independencia argentina es una de las más antiguas de } \\
\text { Sudamérica. }\end{array}$} & Alto \\
\hline & & Medio \\
\hline & & Bajo \\
\hline \multirow{3}{*}{$\begin{array}{l}\text { Novedad absoluta } \\
\text { (o valor terminal) }\end{array}$} & \multirow{3}{*}{$\begin{array}{l}\text { El Virreinato del Río de la Plata fue el último creado en } \\
\text { América. }\end{array}$} & Alto \\
\hline & & Medio \\
\hline & & Bajo \\
\hline \multirow{3}{*}{ Novedad relativa } & \multirow{3}{*}{$\begin{array}{l}\text { El Museo del Bicentenario es uno de los más nuevos en } \\
\text { Argentina. }\end{array}$} & Alto \\
\hline & & Medio \\
\hline & & Bajo \\
\hline
\end{tabular}

5 Considérese la propuesta del CICATUR-OEA equivalente sólo a esta primera variable. 


\begin{tabular}{|c|c|c|}
\hline \multirow{3}{*}{ Frecuencia destacable } & \multirow{3}{*}{ La Feria del Libro de Buenos Aires se celebra cada año. } & Alto \\
\hline & & Medio \\
\hline & & Bajo \\
\hline \multirow{3}{*}{ Diversidad } & \multirow{3}{*}{$\begin{array}{l}\text { La Cordillera de Los Andes presenta tres cordones } \\
\text { montañosos diferentes en Argentina. }\end{array}$} & Alto \\
\hline & & Medio \\
\hline & & Bajo \\
\hline \multirow{3}{*}{ Significación } & \multirow{3}{*}{$\begin{array}{l}\text { El Che Guevara representa un ícono de la lucha contra la } \\
\text { injusticia social. }\end{array}$} & Alto \\
\hline & & Medio \\
\hline & & Bajo \\
\hline \multirow{3}{*}{ Funcionalidad } & \multirow{3}{*}{$\begin{array}{l}\text { El Cementerio de la Chacarita alberga la tumba de Carlos } \\
\text { Gardel. }\end{array}$} & Alto \\
\hline & & Medio \\
\hline & & Bajo \\
\hline \multirow{3}{*}{ Sensorialidad } & \multirow{3}{*}{$\begin{array}{l}\text { La Quebrada de Humahuaca fue declarada Patrimonio de } \\
\text { la Humanidad en virtud de su colorido paisaje cultural. }\end{array}$} & Alto \\
\hline & & Medio \\
\hline & & Bajo \\
\hline
\end{tabular}

Ahora bien, las características del recurso turístico definen el tipo de vínculo posible con el visitante y provocarán una determinada actitud. Aquéllos relevantes por su capacidad de impresionar los sentidos establecerán vínculos sensoriales e invitarán a la contemplación; aquéllos interesantes por la información que brindan determinarán vínculos intelectuales y demandarán su interpretación. En la realidad, abundan los casos mixtos.

Estas reflexiones también brindan conocimientos de utilidad para el proceso de conversión del recurso turístico en atractivo turístico: las gestiones apropiadas dependen significativamente de los vínculos y actitudes esbozadas. Así, la interpretación exige algún tipo de intermediación explicativa del recurso al visitante, es decir que requiere el desarrollo de un relato o guión en base a las características sobresalientes del recurso, sea oral (guía de turismo, audioguía) o escrito (folleto, cartel). El relato, en tanto instrumento inmaterial de conversión del recurso en atractivo, suele ganar soporte material en combinación con otros instrumentos de conversión: instalaciones o artefactos (cartel, folleto, audioguía) y actividades (visita guiada). Asimismo, a fin de facilitar la contemplación se recurre a la provisión de instalaciones (ej.: mirador, telescopio, asiento), ocasionalmente relatos y actividades.

\begin{tabular}{|l|l|l|l|}
\hline Vínculo & Actitud & Instrumento & Ejemplo de recurso \\
\hline Intelectual & Interpretación & $\begin{array}{l}\text { Relato } \\
\text { (instalación, actividades) }\end{array}$ & $\begin{array}{l}\text {-Restos de argentinosaurus } \\
\text {-Sitio del avión de los uruguayos } \\
\text {-Desaparecidos de la dictadura } \\
\text { militar }\end{array}$ \\
\hline Sensorial & Contemplación & $\begin{array}{l}\text { Instalación } \\
\text { (relato, actividades) }\end{array}$ & $\begin{array}{l}\text {-Glaciar Perito Moreno } \\
\text {-Laberinto de Borges } \\
\text {-Julio Boca }\end{array}$ \\
\hline
\end{tabular}




\section{ATRACTIVOS TURÍSTICOS}

La literatura turística generalmente equipara las categorías de recurso turístico y atractivo turístico, como se verificó anteriormente. Pero es importante explorar las diferencias. Por una parte, se señala que los recursos son, en castellano, «elementos disponibles para resolver una necesidad o llevar a cabo una empresa. Recursos naturales, hidráulicos, forestales, económicos, humanos» (DRAE, 2001). Se trata de un término de uso en varios ámbitos, como se desprende de la enumeración de la definición: no es exclusivo del fenómeno turístico. Además, aplicado a bienes naturales y culturales, connota la idea de bienes en su estado original, como los naturales, hidráulicos y forestales de la definición.

Recuérdese que en esta indagación se parte de la idea del recurso como un elemento que resuelve necesidades, luego se considera que resuelve necesidades en base a determinados atributos y se arriba a la conceptualización del recurso como un bien con características relevantes. El foco vuelve del efecto a la causa. No se define al recurso turístico por su capacidad de disolver necesidades (aspecto ajeno, dependiente y de difícil análisis), sino por sus rasgos sobresalientes que la provocan (aspecto propio, independiente y analizable).

Por otra parte, el diccionario indica que el adjetivo atractivo significa «que atrae o tiene fuerza para atraer» (DRAE, 2001). Y el verbo «atraer» significa, «dicho de una persona o de una cosa: Hacer que acudan a sí otras cosas, animales o personas» (DRAE, 2001). El diccionario castellano no prevé el sustantivo «atractivo» en el sentido de atractivo turístico, aunque indudablemente su uso está extendido en el mundo del turismo. En este caso, sí se trata de un término específico del ámbito turístico.

Pero sí existe el sustantivo attraction en inglés y ampliamente se usa para tourist attraction: «an interesting or enjoyable place to go or thing to do» (Oxfrod, 2000: 72); por lo que se infiere que probablemente atractivo turístico sea un anglicismo. Obsérvese que la definición inglesa califica al objeto de interesante o disfrutable, en línea con los dos vínculos comentados entre recursos y turistas: intelectual y sensorial. También introduce la opción de que lo interesante o disfrutable no sea algo que se visita sino algo que se hace, es decir, una actividad turística ${ }^{6}$.

Existen recursos turísticos que no equivalen a atractivos turísticos. Se encuentran «disponibles para resolver una necesidad» pero sin «hacer que acudan a sí personas». Son relevantes, pero no provocan un viaje: para que eso ocurra, es necesario que el recurso sea conocido y sea visitable. Por el contrario, no se conciben atractivos turísticos que no constituyan recursos turísticos; esto es, bienes que motiven un desplazamiento sin pretender satisfacer necesidad alguna: se emprende un traslado con la expectativa de extinguir una necesidad, más allá de que eso ocurra finalmente.

Así, los recursos turísticos originan atractivos turísticos; tanto como los atractivos turísticos se sustentan en recursos turísticos. Este proceso de transformación del recurso en atractivo consiste en hacer que el recurso sea conocido y sea visitable, como se expuso. Registrar un recurso, gestión que aquí se denomina identificación, supone acciones de reconocimiento y valoración. Hacer visitable un recurso o facilitar la experiencia turística, gestión que aquí se refiere como conversión, implica la provisión de instalaciones y/o el

6 Más adelante se verá la excepción de los atractivos creados.

Cuadernos de Turismo, 35, (2015), 335-357 
desarrollo de un relato (y aún de actividades, como se verá), desde el ámbito público o del privado. En consecuencia, los atractivos turísticos son recursos turísticos convertidos.

Luego, en línea con Sancho (1998: 131-132) y con distancia de Gurría di Bella (1991: 48), ${ }^{7}$ se considera que la diferencia entre recurso turístico y atractivo turístico no depende de la perspectiva del sujeto, sino de la perspectiva del objeto: un bien es recurso turístico en tanto no haya sufrido un proceso de conversión pero, mediante gestiones deliberadas para favorecer el contacto directo con los visitantes, se transforma en atractivo turístico. La transformación del atractivo en un producto turístico (paquete o combinación) y del producto en macroproducto son procedimientos posteriores.

Recuperamos ahora la definición de tourist attraction y la opción de que el estímulo de la visita turística sea una actividad turística. Frecuentemente, los turistas no se movilizan para apreciar o conocer un recurso, si no para vivenciar un aspecto simbólico de él. A modo de ejemplo, baste considerar al turista de sol y playa, que no dedica un par de semanas en la costa incentivado por características específicas de la arena o del agua marina, sino por causas (tan distintas y sin embargo combinables) de descanso y status, materializadas en el acto de tomar sol. Descanso y status son representaciones propias de ese recurso turístico; esto es: símbolos, imágenes, conceptos, significados.

Es posible que un mismo recurso origine distintas representaciones: así, en tanto la montaña provoca aventura, incita a hacer trekking; pero también sugiere tranquilidad, con lo que invita a emplazar un spa para tomar baños. También, es posible que una misma actividad se sustente en representaciones y/o recursos diversos: es el caso de los baños en aguas calientes, asociables a representaciones de tranquilidad como de salud, tanto al recurso turístico montaña como al de terma. Asimismo, es posible que una misma representación se base en recursos diferentes: en este sentido, la ruralidad es propia de una estancia argentina como del destino turístico Argentina en su totalidad. El último ejemplo es elocuente de que las representaciones también pueden surgir de destinos turísticos, o bien: los destinos turísticos implican representaciones. Por último, considérese que hay recursos propios de cualquier destino e independientes de características naturales o culturales particulares (ej.: la noche, que equivale a diversión y da lugar a la actividad de salir a bailar).

\begin{tabular}{|l|l|l|}
\hline Recurso o destino & Representación & Actividad o atractivo \\
\hline Playa & Descanso y status & Tomar sol \\
\hline Montaña & Aventura & Hacer trekking \\
\hline Montaña & Tranquilidad & Tomar baños \\
\hline Terma & Salud & Tomar baños \\
\hline Estancia & Ruralidad & Pasear en carretas \\
\hline Argentina & Ruralidad & Comer carnes asadas \\
\hline Noche & Diversión & Salir a bailar \\
\hline
\end{tabular}

7 Según Gurría di Bella (1991: 48), un mismo bien es nominado recurso por parte del planificador y atractivo por parte del visitante. Con base en Gunn (1993), Sancho apunta que «los recursos naturales, culturales, etc. son el fundamento para el desarrollo posterior de la atracción» (1998: 131) y que «los recursos en su forma original no son más que la materia prima de futuras atracciones» (1998: 132). 
Las representaciones turísticas constituyen un fenómeno que reclama profusas indagaciones en tanto estímulos fundamentales de la visita, frecuentemente más vigorosos y dinámicos que los mismos recursos turísticos. En relación con los recursos turísticos y las variables utilizadas anteriormente para su análisis (vínculo, actitud, instrumento), obsérvese que las representaciones demandan una actitud participativa, en tanto establecen con el visitante un vínculo vivencial (ej.: procesión, arqueología experimental, compras), ${ }^{8}$ a diferencia de los recursos que, como se indicó, establecen vínculos preferentemente sensoriales e intelectuales. Tal actitud participativa se materializa preferentemente en actividades:

\begin{tabular}{|l|l|l|l|l|}
\hline Elemento & Vínculo & Actitud & Instrumento & \multicolumn{1}{|c|}{ Ejemplos } \\
\hline \multirow{2}{*}{ Recurso } & Sensorial & Contemplación & $\begin{array}{l}\text { Instalación } \\
\text { (relato, } \\
\text { actividad) }\end{array}$ & $\begin{array}{l}\text { Glaciar Perito Moreno } \\
\text { Laberinto de Borges } \\
\text { Julio Boca }\end{array}$ \\
\cline { 2 - 5 } & Intelectual & Interpretación & $\begin{array}{l}\text { Relato } \\
\text { (instalación, } \\
\text { actividad) }\end{array}$ & $\begin{array}{l}\text { Restos de argentinosaurus } \\
\text { Sitio del avión de los uruguayos } \\
\text { Desaparecidos políticos }\end{array}$ \\
\hline Representación & Vivencial & Participación & $\begin{array}{l}\text { Actividad } \\
\text { (relato, } \\
\text { instalación) }\end{array}$ & $\begin{array}{l}\text { Playa = status } \rightarrow \text { tomar sol } \\
\text { Argentina = } \text { ruralidad comer asado } \\
\text { Noche }=\rightarrow \text { diversión salir a bailar }\end{array}$ \\
\hline
\end{tabular}

Retomando con las gestiones necesarias para la obtención de un atractivo turístico, en la realidad se advierte que éstos no siempre provienen de la conversión de un recurso o una representación. En efecto, se ha recurrido a la creación de atractivos turísticos ante: 1. la inexistencia de recursos; 2. la disponibilidad de recursos de baja valoración o de representaciones con poca fuerza; y 3. la disponibilidad de recursos y representaciones que, aunque valiosos y fuertes, no coinciden con el perfil de una determinada imagen de destino deseada (ej.: Museo Guggenheim en Bilbao).

Generalmente, el atractivo creado es independiente del destino turístico; es decir, que pueden ser desarrollados aquí y allá, ya que no tiene vinculación geográfica o cultural con un lugar particular (ej.: atractivos como ferias artesanales; atractivos clonados como megaestatuas de cristos; atractivos que en conjunto originan un macroproducto como turismo de golf y de reuniones; atractivos franquiciados como los Hard Rock Cafe). Estas reflexiones facilitan una clasificación de atractivos turísticos:

Aunque la promoción o publicidad constituirían acciones posteriores a la conversión o creación, en la práctica, abundan los casos de recursos promocionados sin haber sido convertidos (son sólo conocidos). No es poco frecuente asimismo la comercialización de productos turísticos (atractivo más servicios; tanto en versión privada -paquetes-, como

8 Tal participación no necesariamente es físicamente activa (ej.: la actividad de tomar sol, con base en el conjunto de recursos «playa + sol + murmullo del mar» y en representaciones de relax, serenidad, desnudez, status). 
pública -combinaciones-) basados en recursos sólo conocidos. Todas estas irregularidades en la gestión de recursos turísticos merecen mayor atención en futuras indagaciones.

\begin{tabular}{|l|c|l|}
\hline \multicolumn{3}{|c|}{ CLASIFICACIÓN de ATRACTIVO TURÍSTICO } \\
$\begin{array}{c}\text { Recurso o } \\
\text { representación }\end{array}$ & $\begin{array}{c}\text { Tipo de } \\
\text { atractivo }\end{array}$ & \multicolumn{1}{c|}{ Ejemplo } \\
\hline Conocido & - & pub irlandés, presidente de la Nación, aurora boreal, exotismo \\
\hline $\begin{array}{l}\text { Conocido }+ \\
\text { complementado } \\
\text { (instrumento) }\end{array}$ & Convertido & $\begin{array}{l}\text { sitio arqueológico + instalación (pasarela) } \rightarrow \text { parque arqueo- } \\
\text { lógico } \\
\text { cementerio + relato (audioguía) } \rightarrow \text { cementerio autoguiado } \\
\text { río/aventura + actividad (rafting) } \rightarrow \text { río navegable }\end{array}$ \\
\hline $\begin{array}{l}\text { Inexistente } \\
\text { Valor bajo } \\
\text { No estratégico }\end{array}$ & Creado & Festival folklórico, centro de spa, Disneylandia \\
\hline
\end{tabular}

Por fin, se entiende por atractivo turístico:

\begin{tabular}{|c|}
\hline CONCEPTO de ATRACTIVOS TURÍSTICOS \\
\hline $\begin{array}{c}\text { Representaciones y/o recursos turísticos creados } \\
\text { o convertidos (contemplación, interpretación, participación) } \\
\text { para facilitar la experiencia turística. }\end{array}$ \\
\hline
\end{tabular}

Tras la identificación, clasificación y valoración de recursos y representaciones turísticas es posible diagnosticar para cada caso el grado de «conversión» en atractivo turístico, en consideración de las actitudes que provoca y las gestiones desarrolladas.

\begin{tabular}{|c|c|c|c|c|c|c|c|c|c|c|c|c|c|}
\hline \multicolumn{14}{|c|}{ Diagnóstico del Atractivo Turístico DAT } \\
\hline Elemento & Actitud & \multicolumn{4}{|c|}{ Instalaciones } & \multicolumn{4}{|c|}{ Relato } & \multicolumn{4}{|c|}{ Actividad } \\
\hline \multirow{2}{*}{ Recurso } & Contemplación & $\mathrm{E}$ & $S$ & I & $\mathrm{N}$ & $\mathrm{e}$ & $\mathrm{s}$ & $\mathrm{i}$ & $\mathrm{n}$ & $\mathrm{e}$ & $\mathrm{s}$ & $\mathrm{i}$ & $\mathrm{n}$ \\
\hline & Interpretación & $\mathrm{e}$ & s & $\mathrm{i}$ & $\mathrm{n}$ & $\mathrm{E}$ & $\mathrm{S}$ & I & $\mathrm{N}$ & $\mathrm{e}$ & $\mathrm{s}$ & $\mathrm{i}$ & $\mathrm{n}$ \\
\hline Representación & Participación & $\mathrm{e}$ & $\mathrm{s}$ & $\mathrm{i}$ & $\mathrm{n}$ & $\mathrm{e}$ & $\mathrm{s}$ & $\mathrm{i}$ & $\mathrm{n}$ & $\mathrm{E}$ & $\mathrm{S}$ & I & $\mathrm{N}$ \\
\hline
\end{tabular}

$\mathrm{E}=$ excedente, $\mathrm{S}=$ suficiente, $\mathrm{I}=$ insuficiente, $\mathrm{N}=$ nulo.

Así, se evaluará:

Contemplación: es deseable que los recursos que invitan a la contemplación no carezcan de instalaciones suficientes (S). Se sugiere la revisión y mejora en caso de instalaciones insuficientes y excesivas (I, E) y la incorporación cuando no existan (N). La provisión de actividades y relatos es objeto de evaluación en tanto pueden complementar o afectar la propuesta en consideración de su carácter intrusivo.

Interpretación: es deseable que los recursos que invitan a la interpretación no carezcan de relatos suficientes (S). Se sugiere la revisión y mejora en caso de relatos insuficien- 
tes y excesivos (I, E) y su desarrollo cuando no existan (N). La provisión de actividades e instalaciones es objeto de evaluación en tanto pueden complementar o afectar la propuesta en consideración de su carácter intrusivo.

Participación: es deseable que las representaciones que invitan a la participación no carezcan de actividades suficientes (S). Se sugiere la revisión y mejora en caso de actividades insuficientes y excesivas (I, E) y su desarrollo cuando no existan (N). La provisión de instalaciones y relatos es objeto de evaluación en tanto pueden complementar o afectar la propuesta, en consideración de su carácter intrusivo.

A partir de esta herramienta de diagnóstico, se arriba a una propuesta de valoración de atractivos turísticos en relación con el nivel de desarrollo:

\begin{tabular}{|l|l|l|}
\hline \multicolumn{3}{|c|}{ VALORACIÓN de ATRACTIVO TURÍSTICO } \\
\hline Gestión & Tipo de valoración & Valor \\
\hline Suficiente & cualitativa y cuantitativa & Desarrollado \\
\hline Insuficiente & cualitativa y cuantitativa & Semidesarrollado \\
\hline Incompatible & cualitativa & Pseudodesarrollado \\
\hline Nula / Comunicación & cuantitativa & Subdesarrollado \\
\hline Excedente & cuantitativa & Sobredesarrollado \\
\hline
\end{tabular}

En consecuencia, se conciben tres valores de atractivos turísticos:

Desarrollado: representación o recurso suficientemente convertido o creado (en términos cuali y cuantitativos) para facilitar la experiencia turística, particularmente en consideración del vínculo que establece con el turista.

Semidesarrollado: representación o recurso insuficientemente convertido o creado (en términos cuali y cuantitativos) para facilitar la experiencia turística, particularmente en consideración del vínculo que establece con el turista.

Pseudodesarrollado: representación o recurso convertido sin consideración del vínculo que establece con el turista (gestión incompatible; ej.: instalación de carteles explicativos ante un paisaje que invita a la contemplación).

Subdesarrollado: representación o recurso no convertido (equivale a una gestión nula) o sólo conocido.

Sobredesarrollado: representación o recurso excesivamente convertido; es decir, mediante una implementación intrusiva de instrumentos de conversión: instalaciones, relatos o actividades (equivale a una gestión excedente; ej.: superposición de sistemas de cartelería explicativa ante un mismo recurso).

\section{CONCLUSIONES}

A fin de comprender el alcance de las categorías de recurso turístico y atractivo turístico, se analizaron definiciones y clasificaciones de numerosos autores hispanoamericanos y se identificaron, por una parte, coincidencias respecto de aspectos formales y funcionales en perspectiva conceptual. Por otra parte, se detectó que las clasificaciones focalizan en 
los aspectos formales de los bienes, que destinan una categoría específica para bienes naturales pero diferentes opciones clasificatorias para bienes culturales, que suelen omitir bienes intangibles, bienes muebles, personas y grupos humanos, y que ocasionalmente incluyen elementos que no son recursos ni atractivos turísticos. Luego, se avanzó en una propuesta clasificatoria para recursos turísticos con base en los aprendizajes realizados y en otros insumos teóricos (un esquema de sistema turístico anterior de nuestra autoría y la clasificación de patrimonio de la UNESCO). También se expuso un concepto revisado de recurso turístico y se formuló una propuesta de valoración de los mismos, superadora de las jerarquizaciones conocidas y comprensiva de numerosas variables.

Tras considerar las definiciones oficiales de los términos recursos y atractivos se arribó a una diferenciación entre ambos a partir del procedimiento de la «conversión», propia de los últimos. También se observó sobre el fenómeno de los atractivos sustentados en representaciones. Este abordaje permitió considerar asimismo las correspondencias entre vínculos y actitudes de visitantes con recursos o representaciones, así como los tipos de intervenciones turísticas y tipos de gestión habituales. Como resultado de este análisis se presentó un concepto revisado y una clasificación para atractivos turísticos y una herramienta para el diagnóstico del grado de conversión de aquellos que permitió, a su vez, construir un nuevo instrumento valorativo para la figura de los atractivos.

Estas reflexiones abordan temas, saberes y metodologías esenciales y de dominio acaso excluyente de los profesionales del turismo, poco transferidas o cuestionadas en los ámbitos académicos correspondientes. Toda profesión con proyección de aplicación requiere de herramientas metodológicas de diagnóstico y valoración a fin de conocer la realidad a intervenir. Este trabajo se fundamenta en los vacíos detectados en este sentido en las bases de la gestión turística (pública y privada); es decir, en el momento de conocer y evaluar la materia prima a convertir. Sea este desarrollo una invitación a repensar y profundizar los fundamentos del turismo y la turismología como disciplina científica o, al menos, como fenómeno de estudio y gestión.

\section{BIBLIOGRAFÍA}

ABAL DE RUSSO, C. (1997): Introducción al patrimonio cultural. Mendoza, Ediciones Culturales de Mendoza-Subsecretaría de Cultura-Gobierno de Mendoza.

ACERENZA, M.A. (1984): Administración del Turismo-vol. 1. Conceptualización y organización. México, Trillas, (3ra. reimpresión, 1994).

ALTÉS MACHÍN, C. (1995): Marketing y turismo. Madrid, Síntesis.

BOSQUET, D. (2005): «Patrimonio cultural intangible», en Ruiz, M.C. (Comp.), Patrimonio Cultural. Mendoza, Ediciones Culturales de Mendoza-Subsecretaría de CulturaGobierno de Mendoza.

BOULlón, R. (1985): Planificación del espacio turístico. México, Trillas (1ra. reimpresión, 1991).

BURKART, A. J. y MEDLIK, S. (1981): Tourism: Past, Present and Future. Londres, Heineman.

CÁRDENAS TABARES, F. (1991): Proyecto turísticos. Localización e inversión. México, Trillas (2da. reimpres., 1996). 
CIT, s./f., «VII Congreso Interamericano de Turismo» (citado en Ramírez Blanco, 1998). CLAWSON, M. y KNESTCH, J. L. (1966): The Economics of Outdoor Recreation. Baltimore, John Hopkins University Press (citado en Sancho, 1998).

DNT (1970): Diccionario de terminología turística. Buenos Aires, Dirección Nacional de Turismo.

DOMÍNGUEZ de NAKAYAMA, L. (1994): Relevamiento turístico. Propuesta metodológica para el estudio de una unidad territorial. Santa Fe, Centro de Estudios Turísticos-Instituto Superior Sol.

DRAE (2001) Diccionario de la Real Academia Española (22 ${ }^{\circ}$ ed.). Espasa Libros.

GARCIÁ SILBERMAN, Ana (1970): «Clasificación de los recursos turísticos», Boletín del Instituto de Geografía, vol. III, México.

GUNN, C. (1993) «Megatrend Attraction Myths and Fallacies», World Travel and Tourism Review, vol. 3.

GURRÍA DI BELLA, M. (1991): Introducción al Turismo. México, Trillas (1 ra. reimpres., 1994).

IMIT (1974): «Apuntes para el curso de introducción al estudio del turismo». México, Instituto Mexicano de Investigaciones Turísticas (citado en Ramírez Blanco, 1998).

NAVARRO, D. (2007a): «Conceptualizaciones operacionales», en TurPlan II-Plan de Desarrollo Turístico de la Provincia de Mendoza. Mendoza, Subsecretaría de Turismo-Ministerio de Turismo y Cultura-Gobierno de Mendoza y Consejo Federal de Inversiones.

NAVARRO, D. (2007b): «Sistema Turístico Mendocino», en TurPlan II-Plan de Desarrollo Turístico de la Provincia de Mendoza. Mendoza, Subsecretaría de Turismo-Ministerio de Turismo y Cultura-Gobierno de Mendoza y Consejo Federal de Inversiones.

NAVARRO, D. (2010): Imagen Turística Argentina. Política turística como política exterior. Mendoza, Editorial de la Universidad del Aconcagua.

OMT (s./f.): Los recursos de los destinos turísticos. Organización Mundial del Turismo, Themis, Institute for Quality in Tourism Education, Master en Alta Gestión en Política y Estrategia de Destinos Turísticos, Postgrado en Desarrollo Sostenible de los Destinos Turísticos, Especialización en Planificación delos Destinos Turísticos.

OXFROD (2000): Oxford Advanced Learner's Dictionary of Current English ( $6^{\circ}$ ed.). Oxford University Press.

RAMÍREZ BLANCO, M. (1998): Teoría general de turismo. México, Diana (1ra. ed., 1981).

RUIZ, M.C. (Comp.) (2005): Patrimonio Cultural. Mendoza, Ediciones Culturales de Mendoza-Subsecretaría de Cultura-Gobierno de Mendoza.

SANCHO, A. (Dir.) (1998): Introducción al turismo. Madrid, Organización Mundial del Turismo.

SWARBROOKE, J., (1995): The Development and Management of Visitor Attractions. Londres, Butterworth Heinemann.

WALLINGRE, N. y TOYOS, M. (2010): Diccionario de Turismo, Hotelería y Transporte. Buenos Aires, Ediciones Universidad del Salvador.

ZIMMERMANN, E. (1957): Recursos e industrias del mundo. México, FCE.

ZIMMERMANN, E. W. (1933): World Resources and Industries. Nueva York, Harper and Brothers. 
